\title{
Research on the Contents and Indexes of Reservoir Operational Security
}

\author{
Jingchun Feng, Zhongnan Duan \\ Business School, Hohai University, Nanjing China \\ E-mail:dzn198688@sina.com \\ Received September 26, 2010; revised November 7, 2010; accepted November 8, 2010
}

\begin{abstract}
Reservoirs play an important role in the development of economy and society, as well as the maintenance of ecological balance. The reservoir operational security can make every function of reservoirs fully played. This paper makes a systematic analysis on the meaning of reservoir operational security and builds up a framework system of it from the perspective of organization and system. On this3 basis, the paper researches the contents and indexes of reservoir operational security from the microscopic, intermediate and macroscopic aspects. The results of this paper provide a foundation for further research on reservoir operational security management.
\end{abstract}

Keywords: Reservoir Operational Security, Security Content, Security Index, Framework System

\section{Introduction}

At present there are numerous reservoirs in our country, and they play an important role in the construction of national economy. But it is not ideal in terms of the condition of the security of reservoir operation [1-5]. It is necessary to research the security of reservoir operation to guarantee the reservoir comprehensive benefits can be exerted adequately. Consult present related research results we find that the majority scholars only limit regarding research of the reservoir security to some constituents of the reservoir, or they research the question which exists to the reservoir operational guidance directly. In a word they can't consider the reservoir operational security problem from the overall situation angle, but only emphasis some aspects of reservoir operation one-sidedly [1-5]. In this paper, the content of the security of reservoir operation has been analyzed from the viewpoint of system with the purpose of proposing the content of reservoir operational security from the deep level, constructing a comprehensive, concrete concept system of reservoir operational security.

\section{The Content of the Reservoir Operational Security}

The reservoir operational security is referred to the reservoir is at one condition that the project, the personnel and so are not to be dangerous in reservoir operational process, and each interior constituent of the reservoir system can be complete, ordered, stable and can develop with external system harmoniously, sustainably.

There are three aspects of the reservoir operational security content, respectively the microscopic, the intermediate and the macroscopic. The microscopic is referred to the security of reservoir system including the security of project entity and ancillary facilities and the efficiency of reservoir operational management. The intermediate is referred to the reservoir operation can meet the need of the economy and society development including the display of reservoir economic efficiency as well as safeguard to personal and property security of downstream people. The macroscopic is referred to the security of reservoir operation is established on the basis that the reservoir can coexist with the ecosystem harmoniously. The content of reservoir operational security is shown in Figure 1.

\section{The Microscopic Aspect of Reservoir Operation Security}

\subsection{The Security of Project Entity}

As an engineering system, the reservoir security should be considered with systematic view. The most essential requirement of the reservoir security is that each project 


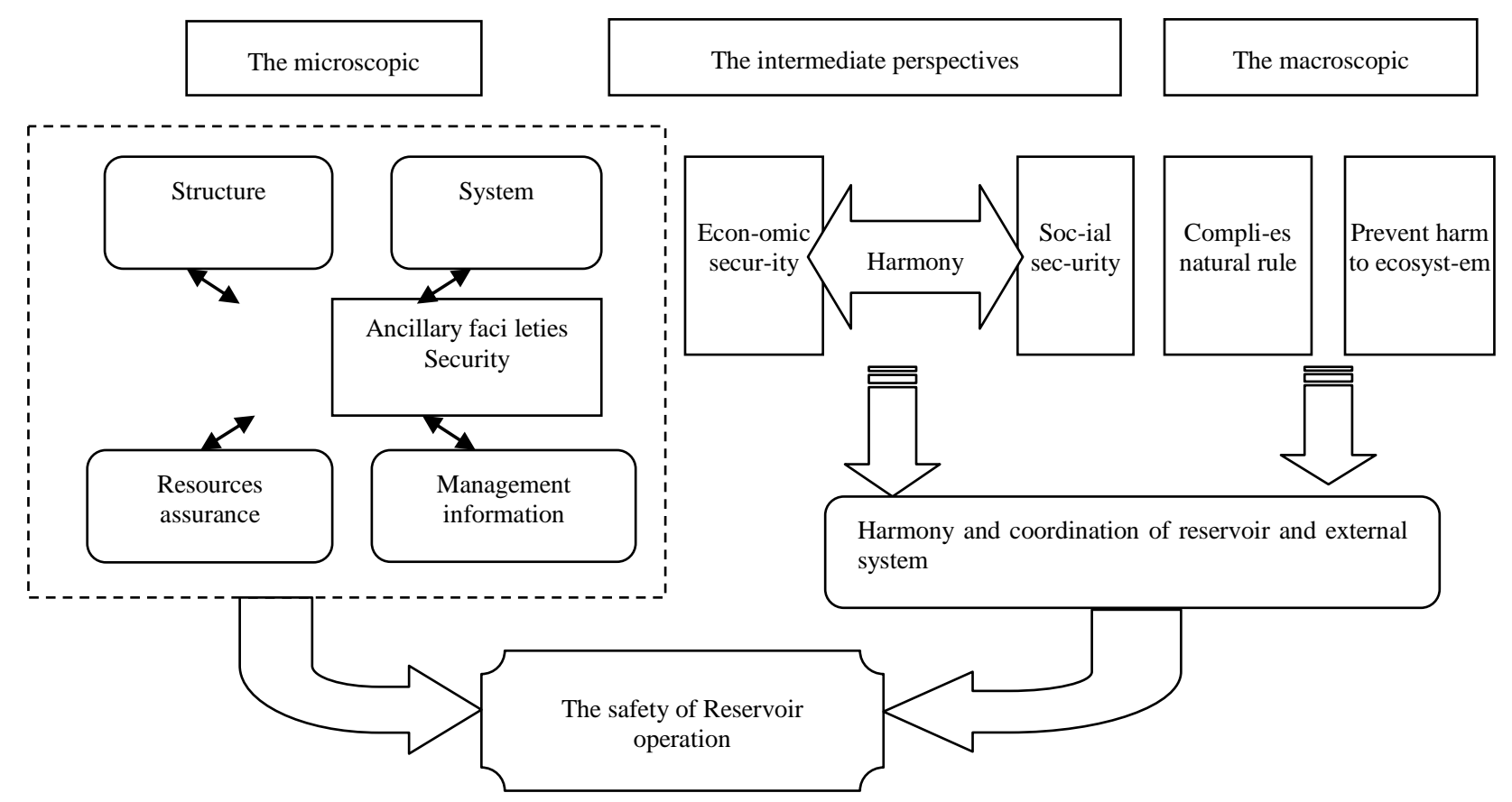

Figure 1. the content of Reservoir operational security.

entity of the reservoir system is in safe [6]. The security of project entity is referred to various engineering structures as well as the constructions achieve the construction standard and the quality requirement of the construction specifications and the design requirements, and the other requirement is that project maintenance is good and the project can run normally without hidden danger.

\subsubsection{The Contents of the Project Entity Security}

1) The quality of the reservoir entity meet the requirements. Its quality is reliable and meets the lowest national and industry standard for reservoir operation. Quality standards for dam include no cracks, abnormal deformation, leakage and other quality problems. The other quality standard is that the construction of the project entity follow a reasonable course of the construction procedure, use the highly effective construction technique, form the perfect project archive file.

2) The appraisal of project entity security is rigorous. The appraisal of influencing factors of the reservoir project entity security must be rigorous, because this is direct relation to our definition of whether reservoir can run safely. By no means all quality flaws or management faults can create the ruinous attack to the reservoir security directly. The security problem we must pay attention to is that may cause an irreversible harm to reservoir, whereas the small problems which can be corrected promptly and has little influence on the reservoir security don't belong to the scope we study.

3) Dynamic characteristic of the project entity security.
Reservoir operation can be influenced by many factors easily, so its security status is changing constantly. For a reservoir, it requires not only the current security but also the sustained security in long future. And the reservoir needs to have one kind of function that it can momentarily make the adjustment and maintain the safe condition along with the change of each kind of factor.

\subsubsection{The Indexes of the Project Entity Security}

1) Integrity of project entity. As a complex system, the reservoir is composed of many project entities with different function. Whether reservoir can exist safely and its operation benefit can display efficiently is first decided by the integrity of category and quantity of project entity. In the actual operation process, the integrity of reservoir project entity must manifest the integrity of the function.

2) Stability of project entity. Stability of project entity is referred to various project entities can maintain continually in safe and steady in the operation process. As influenced by extraneous factor in the daily time, the condition of various project entities of reservoir changes unceasingly, therefore the whole security of reservoir is decided by stability of various project entities. We should establish perfect security monitor and inspection system, and monitor the stability problem of various project entities real-timely. After finding the problem, we should carry on the careful analysis to the question adopting the corresponding security system, and take the corresponding solution measure. 


\subsection{The Security of Ancillary Facilities}

The security of reservoir entities depends on the integrity, coordination and integration of the ancillary facilities to some extent. Reservoir project entities must be collaborative with the ancillary facilities to ensure the role, once they are out of the relationship, not only the effect cannot be guaranteed, but also may cause significant security problems. Such as the operation of hydrological monitoring facilities, automatic alarm system and communication facilities run into problems will inevitably affect the reservoir security.

\subsubsection{The Contents of Ancillary Facilities Security}

According to the requirements of reservoir system operation, we provide with a sufficient number of ancillary facilities, establish and implement corresponding operation management plans to ensure that all ancillary facilities and various functional entities of reservoir to work cooperatively. The contents of ancillary facilities security include as follows.

1) The operation of ancillary facilities. The security of ancillary facilities of reservoir system is based on well operation of their own system, which can ensure their contribution to the whole system. The operation of ancillary facilities also requests to meet the basic requirements such as integrity, order, stability and so on.

2)Ancillary facilities and project entities work cooperatively. The impact of ancillary facilities is reflected as follows, first is cooperated with project entities and form relevant working mechanism so as to play the major project entities function of reservoir system; the second is as a carrier to manage work implementation, which can improve the operation management efficiency effectively; the third is to supervise the state of project entities to assure project security.

\subsubsection{Indexes of Ancillary Facilities Security}

1) Integrity of ancillary facilities. The operation of reservoir systems is complex extremely, and its functions are also diverse, which requires reservoir system and various ancillary facilities work cooperatively. To play each specific function of reservoir need to cooperate with the ancillary facilities. The comprehensive benefit of reservoir is based on the function of ancillary facilities system. So the basic requirement is the integrity on category and quantity of ancillary facilities of reservoir system.

2) System integration of ancillary facilities. The operation of complex project such as reservoir should be guided with system views. Integration in essence is a kind of thought and method guided by systematic. Integration emphasizes human active behavior and double function as well as evolutionary adaptation after integration, but also contributes to solve complex system problems and improve macro-function of system. System integration of ancillary facilities is to study how various ancillary facilities of reservoir be together organically and realize complement of benefit, function as well as structure fully so that integrated body can be qualitative change and the overall effectiveness of the reservoir system is enhanced greatly.

\subsection{The Security of Reservoir Operation Management}

Project entity security is the basis of reservoir security, while the security of reservoir operation management is the core of reservoir operation security. There will be a variety of security issues appear in reservoir operation, and the implementation of efficient management methods and measures is an important guarantee to ensure the reservoir operation security $[7,8]$.

\subsubsection{The Contents of the Security of Reservoir Operation Management}

Security of reservoir operation management is reflected in reasonability of organization structure, sound institution system, assurance of resource input, and fluent information.

1) Reasonability of organization structure. According to organization theory, system's goal determines system's organization; organization is the decisive factor for goal achieving. Organization is a means to achieve goal. Therefore, the efficiency of reservoir operation management depends on whether its organization structure is reasonable [9]. The reasonability of the organization structure reflects in the following three aspects. First: the choice of organization model meets the management requirements. The selected organization model can provide a clear organization command relationships from top to down for reservoir operation management. Second: setting all levels of management positions reasonably based on the determined organization structure with suitable people who have professional knowledge and skills. Third: work tasks and management functions have a clear labor division. Everyone knows their specific tasks and each work has a specific staff.

2) Sound institution system. Institution is the rule and norm of behavior that all members in organization system must abide in the daily work. The so-called no rules no standards, therefore, in order to ensure the effective implementation for reservoir operation management, there must be appropriate and sound institution system. The existence of institution system of reservoir security management provides norms of behavior for all reservoir 
staff, and makes relevant laws and regulations, mandatory standards, security measures technology carried out, provides a guarantee for reservoir security management in institution.

3) Assurance of resource input. The implementation of the management must have a physical carrier as a support, and resources inputting is the most basic guarantee. Reservoir security management resources inputting not only includes the corresponding human, material and financial resources, but also includes the advanced and efficient operation management technology.

4) Effective management of information. Information management has become an important part in project management; the efficiency of reservoir operation management is determined by the efficiency of information management largely [10]. The contents of information management security of reservoir are reflected in the following three points. First one is the completeness of the information. There is a large number of information during the construction and operation phase which have played an important role in the reservoir security. Second is the timeliness of information processing. Information formed in various stages of reservoir operation can be processed timely so that will not harm reservoir security. Third is the effectiveness of information processing. The methods and techniques for processing information should meet the relevant provisions requirement, so as to ensure the efficiency of information processing.

\subsubsection{Indexes of Reservoir Operation Management Security}

1) Organization structure model. Selection of organization structure is not fixed and project with different purpose is suitable for different organization structure model. Making more reasonable choices based on analyzing and comparing the specific objectives, task conditions, operation environment and other factors of reservoir operation. Such as the function-type organization, project-type organization, matrix-type organization, composite tissuetype organization, different forms of organizations have different applicable scope. Reasonable reservoir project organization should clear management tasks and division of functions of all parties, determine the organization flow and work logic in inter-organizational processes of reservoir operation management, thus promoting personal, material and information flow between the external and internal of organization run well and making the realization of organization's objectives possible.

2) Institution system. One is the establishment of institution system. According to all work requirements during reservoir security operation, implement corresponding institution safeguards, and make all of these institutions form a system, the formation of system could cover all daily work, and provide useful guidance for the work; the other one is the institution implementation system. Reservoir security management regulations and practices made by primarily principal person must be behavioral norms for all managers of the top-down reservoir organization. Therefore, corresponding measure is needed, such as strengthening supervision of management and holding scheduled meetings, etc. to emphasize the implementation of the institution.

3) Resource planning. For investing in human, material and financial resources, first is to have a detailed and workable investment plan, this plan can make overall arrangements for the input quantity, quality and time from macroscopic, which are benefit to determine later program such as procurement, supply, installation, commissioning. Second is that the investment of manpower, material and financial resources can meet the need of security management that means the type, quantity, quality of input all meet the demand.

4) Information technology means. One is information management manual. Reservoir security management personnel nail down information management goals and tasks as well as the division of tasks and management functions through writing information manual, realizing scientific and orderly information security management. The other one is flow chart for information system security management. Through the design of flow chart, all kinds of information processing methods and procedures can be applied to improve the efficiency of information processing.

\section{The Intermediate Aspect of Reservoir Operational Security}

The reservoir is a product of humanity transforms and use of natural, its construction and operation process is a purposeful, calculated and organized humanity activity. The reservoir has both the natural and social attribute. As one kind of humanity project behavior, the reservoir manifests the sociality much more. The relationship between reservoir and economic society manifests specifically in: the reservoir is an important component of the rivers and streams flood prevention system, is an important project measure which regulates space and time distribution of the water resources and optimize water resources disposition. And as an important infrastructure of national economy, the reservoir provide the powerful safeguard for the economy development in flood prevention and drought resisting, production and living water, electricity generation, cultivation, traveling and so on[11] [17]. The intermediate aspect of reservoir operational security is referred to the reservoir operation can meet economy society's need, including economy security and 
society security, as well as harmony of each other.

\subsection{The Contents of the Intermediate Aspect of Reservoir Operational Security}

1) Economy security. Economy security manifests in: Firstly, the construction cost of reservoir can be compensated by the income which obtains in reservoir operation after completion. This is the key whether the construction permission of reservoir can be obtained. During the feasibility study period of reservoir, we need to guarantee the economical security of the reservoir construction through repeatedly checking calculation and overall evaluation. Secondly, reservoir operation process efficiency. The economical goal of reservoir construction generally includes electricity generation, water supply, shipping, cultivation, traveling and so on. The realization and its degree of each kind of economical goal of reservoir in operation phase is important manifestation of economic security [11].

2) Society security. Society security manifests in: Firstly, The reservoir downstream people's personal and property security can be guaranteed. On the one hand one of reservoir construction goals is flood prevention, so the realization of flood prevention after the reservoir completion is manifestation that the reservoir downstream people's personal and property security obtains guarantee. On the other hand after the reservoir completion, there is high water head and the increase of water volume in flood season, which will have certain hidden danger inevitably to the downstream people's security. We should ensure security in the high water season and eliminate the threat of flood to downstream people security by the reasonable flood prevention dispatch. Secondly, the immigration project security. The reservoir construction possibly involves to the upstream immigration problem, For example the Three Gorges Reservoir construction causes the massive personnel to be compelled to immigrate. The immigration project is a complex project, Settler's life custom and cultural idea is compelled to be changed, So it possibly cause the discontented mood then affect society's stability and unity. Completing the immigration work, stabilizing immigration's mood, meeting the immigration's request as far as possible is the important measure to guarantees the social stability.

3) The harmony between economy security and society security. The reservoir economy security and society security must unify dialectically not oppose mutually. Economy security is foundation of society security and society security has a certain degree of economy security. The reservoir overall safe must take consideration to economy security and society security. But according to the request of constructing the harmonious social policy in our country, the society security dominates above the economy security. For example the huge project like the Three Gorges Project and the divert water from the south to the north which have the strategic significance to the national development, What it primarily considerate is the society security problem, but not only pursues its short-term investment yield or the sole economic utility. Therefore the starting point of reservoir security control thought is on the basis of guaranteeing downstream people personal and property security and social stable, pursuing the economic efficiency as far as possible and guaranteeing economy security. The harmony between economy security and society security is guarantee of the intermediate aspect of reservoir security.

\subsection{Indexes of the Intermediate Aspect of Reservoir Operational Security}

The existence value of reservoir is to manifest its econsociality. Only understand and grasp correctly the nature and characteristic of reservoir operation as an economy and society action, take seriously to integrating the diversified economy and society behaviors in the reservoir operation process effectively and constructing good project order, can we improve the intermediate aspect of reservoir operational security.

1) Society responsibility. The reservoir operation superintendent and the policy-maker must set up the society responsibility, carry on the reservoir operation as society host, emphasize the society responsibility of reservoir and realize the reservoir society value. The strategic formulation of reservoir operation must be systematic, scientific and secure.

2) Economy benefit. The display of reservoir operation benefit needs to consider fully the socio-economy development of the entire basin and influence to industry, agricultural as well as city and countryside resident's life, value weight project economic efficiency, and make the comprehensive and correct appraisal. Cause the reservoir comprehensive benefits appraisal to conform to economic efficiency, social efficiency, environment and the ecological benefit.

3) Coordination of all quarters. The reservoir operation involves numerous relational main body including nation, profession, project legal person, operational guidance personnel as well as social populace and immigrant influenced by reservoir. The more main bodies, the more complex relations, therefore we need to coordinate the relations of numerous main bodies in reservoir operational guidance. Take "human-water harmony" as the instruction, clear about the reservoir operation foundation is to safeguard people's personal and property secu- 
rity as well as society stability [13].

\section{The Macroscopic Aspect of Reservoir Operational Security}

Reservoir construction and operation is carried out in the natural environment, therefore it bound to have direct impact on nature, environment, ecology. With the deterioration of ecological environment in recent years, the quality of human survival and sustainable development has been affected more and more seriously. These questions aggravated people's concern on the ecosystem security. The macroscopic aspect of reservoir operational security requires reservoir operation will not cause serious destruction to the ecological environment, and achieve harmonious coexistence of reservoir and the ecosystem.

\subsection{The Contents of the Macroscopic Aspect of Reservoir Operational Security}

1) Complies with the objective natural ecology rule. It is the basic guarantee of the reservoir ecological security that the reservoir construction and operation complies with the objective natural ecology rule. In the traditional project idea, we have always stressing to conquer the nature, but the nature in turn gives us severe retaliation. Coexist with the nature harmoniously is the new path which we should attempt, is also the effective device to protect the ecosystem.

2) Prevent harm to the natural ecosystem effectively. The impact of reservoir engineering to the ecology is multifaceted: for example big area of vegetation in reservoir upstream is submerged; the dam construction prevented the migration fish to return to the birth place to spawn; the habitat of upstream biology is destroyed; the water distributed situation is affected; What's more significant disaster like earthquake may be caused. In the reservoir operation process, depending upon the scientific reservoir dispatcher and management method, we use each kind of advanced ecology water conservation technology, and prevent harm of reservoir to the ecosystem, ensure ecosystem security, this is the important content we should consider to guarantee the macroscopic aspect of reservoir security [14].

\subsection{Indexes of the Macroscopic Aspect of Reservoir Operational Security}

1) Project ecology view. The reservoir operation and management idea needs to transform from the project water conservation to the ecology water conservation, set up scientific project ecology view. We should make mul- tiple analyses to the consequence of the reservoir activity, and take it as the bounded condition of the reservoir operation activity. In value orientation, coordinate the ecology value and the construction value, cause mutual coordination and promotion of socio-economy function of the reservoir and ecological function of the nature.

2) Philosophy of engineering. Under the new historic condition, we should ponder reservoir operational guidance from the philosophy angle. The traditional project thought is only to emphasize one-sidedly conquering the nature, while conquer the nature we also suffer the natural retaliation. The harmonious coexistence of reservoir and the natural ecosystem must manifest philosophy of engineering. [15].

3) Project harmony view. The project harmony view not only requests project own harmony, also external system harmony. [16] From sustainable development angle, explore earnestly and research deeply relation of reservoir operation and the natural system. Quantizing concretely the disturbance of reservoir operation to the nature and anti-jamming ability or bearing capacity of nature itself, grasp both coordination [18].

\section{Conclusions}

1) Reservoir plays an important role in the national economy construction in China. Reservoir operation and management should be based on the security theory and in the systematic perspective, at the same time follow the sustainable development strategy in order of ecological continuance, society continuance and economic continuance, so as to promote the harmonious development of economy and society and improve the ecological environment.

2) The connotation of reservoir operational security has wide-ranging contents. Internal system includes the security of reservoir itself and the corresponding management work; outside system contains the harmonious development of the reservoir, economy, society and ecosystem.

3) From the overall and macroscopic perspective, the connotation of reservoir operation security takes the various contents and corresponding indexes into consideration. It provides a theoretical basis for further research of the reservoir security management, also makes contribution to the construction of the security evaluation index system of reservoir operation.

\section{References}

[1] Wu Xisheng. Strengthen the safety management and exert comprehensive benefits of small reservoir. Hebei Water Resources, 2000(2): 39-40. 
[2] Li Huijun. On the reservoir Safety problems and countermeasures .Information Technology, 2009(1): 58.

[3] Li Lei, Lu Yunqiu. China's dam safety and management practice and challenge. Scientific \& Technical. 2003(11): 59-62, 5.

[4] Lv Jinbao, Zhang Linjian, Fu Lisheng. Provinces and countermeasures of management of small reservoirs in Jiangsu. Yangtze River, 2008(8): 99-100, 110.

[5] Zhu Xiaoyuan, Lv Le. Safety Management of Reservoir, Zhejiang Province, problems and suggestions. Water resources development research, 2008(5): 36-39.

[6] Wang Liancheng. Theory of engineering system. Beijin: China Aerospace Press, 2002.

[7] Ministry of Water Resources. Notice on strengthening the management of reservoir safety. 2006(4)

[8] Ministry of Water Resources construction and management of water. Views about strengthening management of small reservoir. 2002(5).

[9] W. Richaed. travers. Organization theory [M]. Beijing: Huaxia Publishing House, 2002.

[10] Dingshizhao. Introduction of water resources engineering information[M]. Beijng: China Building Industry Press,
2005.

[11] Xuhuiling. Water project construction and soci-economy development. sichuan water resources,2008(3): 63- 65.

[12] Zeng Jiansheng. People-centered model of Resettlement Management - A Case Study in Guangdong reservoir resettlement mode. Hunan: seeker, 2006(7): 78-81.

[13] Cai Qihua. People and water. Yangtze River, 2006(5): 1-3.

[14] Suo Lisheng. Water protection and ecology construction. China water, 2006(2): 11-13.

[15] Yin Ruiyu. Engineeering and philosophy. Beijing: Beijing: Institute of Technology Press, 2007.

[16] Feng Jingchun, Shao Xiang, Liu Hongbo, Qi Changchun. The content and hiberarchy of water resource engineering harmony. China water resources, 2009(9): 19-23, 29.

[17] Maciej Zalewsk. Ecohydrology the scientific background to use ecosystem properties as management tools toward sustainability of water resources [J]. Ecological Engineering, 2000(16): 35-37.

[18] Bossel H. Indicators of sustainable development, Theory, method, applications [M]. Winnipeg: International Institute of Sustainable Development, 1999. 